\title{
Why Research in Family Medicine? A Superfluous Question
}

\author{
Jan M. De Maeseneer, MD, PbD \\ An De Sutter, MD
}

Department of General Practice and Primary Health Care, Ghent University, Belgium

\begin{abstract}
The ultimate answer to the question, "Why research in family medicine?" is to provide better care for our patients. Through research we want to improve quality of primary care by improving our understanding and practice of it. This research will inevitably be specific for family medicine as family medicine is a specific discipline. In this article we first explore what makes family medicine a specific discipline. In a second part we present a framework to grasp the various research questions that must be answered to achieve the complex and multifaceted goal of improving quality of care.

Family medicine is a specific discipline for 3 reasons: it has a unique epidemiology, the context of care is important, and it has a strong link and responsibility to the community.

Quality of care is a complex and multidimensional concept that raises diverse research questions. We propose to map these questions within a framework defined by the 3 dimensions of the Donabedian triangle-structure, process, and outcome-and within each of these dimensions by 5 foci-basic knowledge, diagnostic and therapeutic problem solving, practice implementation, policy context, and education. This framework may help to make the various research questions operational and to point out the gaps in our research.
\end{abstract}

The questions and answers should be relevant to daily practice and comprise all domains of family medicine so that eventually most of our daily actions in practice will be underpinned with medical, contextual, and policy evidence and contribute to the improvement of the quality of care.

Ann Fam Med 2004;2(Suppl 2):S17-S22. DOI: 10.1370/afm.148.

\section{INTRODUCTION}

$\mathrm{F}$ amily physicians are, on daily basis, involved in a huge variety of activities. They treat patients with acute disease, reassure patients with self-limiting disease, take care of chronic patients, counsel patients with psychorelational problems, and prevent health problems through information and screening programs. They take part in interdisciplinary teams managing the care of a terminally ill patient, organize 24hour continuity of care, help to identify health threats in the community, strive for equity and accessibility of health care, and advocate health care for illegal residents. Family physicians invest considerable personal commitment and energy in a wide spectrum of interventions.

A critical review of the activity undertaken during 1 day in a family practice will show that some actions are underpinned by sound scientific evidence, many are based on consensus, some are founded on common sense, and a few come from personal intuition. The literature shows that many pertinent questions in family medicine stay unanswered, and much scientific evidence is not at all relevant for daily patient care in family practice.

In this article we start from the question, "Why research in family medicine?" In fact, the question in itself is superfluous and may illustrate 
the lack of self-confidence of this discipline. After all, nobody asks why research in cardiology or hematology is needed. The obvious answer is that research is a natural part of any scientific discipline, and thus it is also a part of family medicine. Still, the question of what research is specific to family medicine may arise. Could family medicine not find a sufficient scientific base in the results of research in pediatrics, internal medicine, geriatrics, and gynecology? This question is also superfluous; the obvious answer is that family medicine is a specific scientific discipline, not an assembly of parts of other disciplines. The 2002 European Wonca definition of general practice/family medicine clearly states: "General practice/family medicine is an academic and scientific discipline, with its own educational content, research, evidence base, and clinical activity."1

Ultimately, the only answer to "Why research in family medicine?" is to provide better health care for the patients. Through research we want to improve the quality of primary care by improving the understanding and practice of it. Yet, quality is a complex concept, and research to improve quality will inevitably be extensive and multifaceted with many diverse questions to be answered.

In this contribution we start with an illustration of the specificity of family medicine research. In the second part we will present a framework that can help to map and make operational the various research questions that must be answered to improve the daily care for patients.

\section{WHY SPECIFIC RESEARCH IN FAMILY MEDICINE?}

\section{Unique Ecology}

First of all, family medicine has a unique ecology. ${ }^{2}$ The family physician as the first contact for all kinds of health problems deals with a huge variety of problems, mostly in the early stages. Symptoms are vague, prevalence of serious disease is low, many problems are selflimiting, and comorbid conditions are often present. As a result, decision making in primary care is completely different from that in secondary care settings because, for example, low probabilities reduce the predictive value of many diagnostic tests in family practice.

The importance for research on the epidemiology of family practice can be illustrated by looking at the randomized controlled trials (RTCs), which are universally considered to be the method of choice for determining the efficacy and effectiveness of interventions ${ }^{3}$ and the basis of evidence based medicine. Existing RTCs are often of little use for the family physician. Most study patients have well-defined diseases and meet specific inclusion and exclusion criteria, consequently; most patients in family medicine will not fit the inclusion criteria. Their disease is not yet sufficiently developed, they have other concurrent health problems, or they are older than the patients in the trials. It is often difficult to find a study that applies to a family medicine patient. Researchers in family medicine have so far been reluctant to use intervention studies, favoring instead observational study designs. ${ }^{3}$ As a result, randomized controlled trials in primary care are badly needed, such as trials that start from common complaints and symptoms, trials with few exclusion criteria, and trials that include a variety of patients who are comparable with the average family practice population. Diversity in the study population can be an advantage, instead of a problem. These trials should ideally be large because small trials tend to exaggerate intervention benefit. ${ }^{4}$ Yet large randomized clinical trials are not always feasible, and most are costly. Primary care will probably continue to live with the paradox that the rigor of inclusion criteria and patient selection needed for an RCT are completely opposite to daily practice.

\section{Context of Care}

A second characteristic of family medicine is that context is of utmost importance. Nonmedical factors such as the doctor-patient relationship, the cultural context, the occupational context, the support networks, the socioeconomic context, all influence the diagnostic and therapeutic approach and the final outcome. There is, for example, empirical evidence that enhancing patient expectations improves outcomes. ${ }^{5}$

During the past decade the context has changed dramatically-economically, socially, educationally, and sexually. For example, the family, the vital context of most personal illness in the community, exists now in a wide variety of forms - single, one parent, same-sex, double income. ${ }^{6}$ In a postindustrial knowledge-based society, physicians and patients live in new contextual frameworks. Permanent hierarchical structures have been replaced by flexible temporary networks in professional and private life. People live in a risk society, with increasing ecological and socioeconomic risks (eg, increasing unhealthy inequalities) and with increasing individualization. ${ }^{7}$

Research on the importance of the changing context factors is crucial and can best be performed in the family practice setting because the family physician is, as a result of longitudinal relationship with the patients, in a unique position to visualize the influences of the family and other contextual factors on illness and health, such as increasing social isolation, immigration, unemployment, and changes in the environment. ${ }^{8}$

Apart from medical evidence (evidence-based medicine), it is obvious that family physicians need contextual 
evidence to enhance patient care ${ }^{9}$ and only research in family medicine can provide this evidence. This research will have to be interdisciplinary, involving such disciplines as psychology, sociology, and anthropology, and will make use of qualitative research methods. ${ }^{10}$

\section{Accountability to Community}

A third characteristic of primary care is its strong link with and accountability to the community. Not only is primary care directed toward individual patients; it is also concerned with the community. It wants to obtain as much health gain as possible from the limited budgets for as many citizens as possible. To achieve the broadest health gains, more specific research is needed-economic health research to assess cost and utility balances of therapeutic and diagnostic interventions and to study equity and accessibility of health care, and community diagnosis research to help uncover community-related health hazards and suggest interventions in the framework of community-oriented primary care. ${ }^{11,12}$ Results of economic and community research can provide the indispensable policy evidence needed to underpin social and ethical decision making.

Finally, primary care research in itself has a responsibility to the funding society. It should try to return to this society as much as possible by using study design and organization to maximize its possible influence on clinical practice and on patient's well-being. ${ }^{13}$

\section{QUALITY IMPROVEMENT THROUGH RESEARCH: AN OPERATIONAL FRAMEWORK}

The ultimate motive of all research in family medicine is to provide better health care for the patients. To do so, it is necessary to base professional activity on sound knowledge. Research can show how to provide care of high quality for the best outcomes.

Quality is a complex multidimensional concept with various determinants. A comprehensive framework can help to make operational the various questions and to point out the gaps (Figure 1).

Research with a goal to improve the quality of primary care deals with each of the 3 dimensions of the Donabedian triangle ${ }^{14}$ : structure, process, and outcome. Moreover, it comprises 5 important foci: basic knowledge, diagnostic and therapeutic problem solving, practice implementation, policy context, and education.

\section{Structure}

In this framework structure is composed of 3 interrelating components: the society, the individual, and the health care system. Regarding patient care, we look at society as an epidemiological community (characterized in terms of morbidity, socioeconomic status, [un]employment, housing, and other variables), as a cultural community (an anthropological frame of reference), and as a support community (with informal and professional networks). At the level of the individual, a person's knowledge (about the functioning of the body, the mechanisms of disease, the mind-body interaction), skills (coping skills, self-care skills), and attitudes (health perceptions and beliefs) influence clinical care. The third component is the health care system individuals use within the society where both organizational and financial aspects (accessibility, continuity) and characteristics of the health care providers (competence, empathy) influence the care. ${ }^{15,16}$

\section{Process}

Process refers to all the interventions and interactions between patient and provider. Process deals with aspects of communication and medical decision making. Structure and process are inextricably linked in continuous interaction. Communication between patients and physicians, for instance, will be determined not only by the skills of the physician but also by such patient characteristics as the patient's health beliefs and by the organization of the health care system. ${ }^{17}$ Characteristics of the community can play an important role. Cultural-anthropological factors, for example, will often be integrated in communication with migrants and be helpful in decoding symptoms and complaints. The patient's and the physician's expectations and beliefs will influence medical decision making. Decisions, such as whether to prescribe

\begin{tabular}{|c|c|c|c|}
\hline \multicolumn{2}{|c|}{ Figure 1. An operational framework for research in family medicine. } \\
\hline Doci & Structure & Process & Outcome \\
\hline Basic knowledge & & & \\
\hline $\begin{array}{c}\text { Problem-solving } \\
\text { approach }\end{array}$ & & & \\
\hline $\begin{array}{c}\text { Practice } \\
\text { implementation }\end{array}$ & & & \\
\hline $\begin{array}{l}\text { Policy context } \\
\text { Education }\end{array}$ & & & \\
\hline
\end{tabular}


antibiotics for acute sinusitis, can be affected by the patient's faith in antibiotics and the physician's defensive attitude. ${ }^{18}$

\section{Outcome}

Both structure and process will determine the final outcome. There are various relevant outcome indicators, such as symptoms and complaints of the patient, medical parameters (eg, blood pressure, peak flow), quality-of-life indicators (functional status), patient satisfaction, and social equity. How outcome is assessed will greatly be influenced by the paradigm that underpins the medical encounter, how both patient and physician look at health and disease. In the approach to chronic diseases, for instance, there has been a clear paradigm shift from problem-oriented toward goal-oriented care. ${ }^{19}$ For a patient with diabetes, the ability to participate in social life (goal) may be more important than the objective improvement of his impaired glucose metabolism (problem).

Research in family medicine relates to at least one of these dimensions, but within each dimension the research may aim at one or more foci.

\section{Basic Knowledge}

A first important focus is the acquisition of basic knowledge in family medicine. Such research aims at better knowing and understanding what happens with patients when they are confronted with health problems and trying to conceptualize what really matters in health care. The research strategy for this focus is often exploratory, looking to establish the truth of things by observing and recording, by classifying and analyzing. This research develops and uses theoretical models, operational definitions, and measurement tools relevant to the primary care field. Included are classification systems designed to capture the phenomena of family medicine-ways to classify problems, such as the International Classification of Primary Care (ICPC); ways to measure concepts, such as health status; and ways to observe and measure important relationships, such as the physician-patient relationship. ${ }^{20}$

Typical examples are morbidity registration (structure), survey of diagnostic strategies (process), and health status assessment (outcome). These approaches have been instrumental in determining the essential similarities in the clinical challenges to general practice in different countries and under different sociocultural settings. ${ }^{21}$ Much work still is needed to understand better the onset circumstances (What precisely was the situation surrounding the initial signs or symptoms of the patient's discomfort or illness?), concomitant factors (Was there a constellation of interacting or reinforcing circumstances, such as unusual job stress surrounding the onset of the patient's discomfort or illness?), pre- disposing factors (What is known about the patient's genetic, familial, and cultural backgrounds and belief system; what is the patient's theory about the problem?), and precipitation of help seeking (What events, thoughts, or behavior triggered the patient's decision to consult a particular physician at this precise time?). ${ }^{22}$ To tackle these questions, both quantitative and qualitative approaches are needed.

\section{Problem-Solving Approach}

The second focus of research in family medicine is on the diagnostic and therapeutic problem-solving approach. By means of experimental, controlled study designs, the performance of diagnostic and therapeutic interventions is assessed in the primary care setting. In this approach we are looking at efficacy, that is, the way diagnostic or therapeutic interventions work in optimal conditions. The efficacy of many interventions currently used in primary care is not well known or established in studies performed in secondary care, and results are extrapolated to primary care.

An example is the lack of information on predictive values of signs and symptoms ${ }^{23}$ : how useful are particular symptoms at predicting a certain disease, which symptoms are not useful and which rule out disease? Starting from biomedical information (structure), we can start an experiment in the primary care setting by implementing the diagnostic approach (process) to assess the predictive value of a sign or a cluster of symptoms. Different trial designs are now available to assess the relation between therapeutic interventions and outcome. ${ }^{3}$

\section{Practice Implementation}

The third focus deals with practice implementation, that is, the researcher studies in an experimental way specific strategies to encourage implementation of diagnostic and therapeutic problem solving strategies. This kind of experimental research deals with effectiveness-measuring and influencing in real-life conditions the performance of efficacious (what works in ideal settings) strategies. The starting point here is the observation that many evidence-based approaches are not implemented in practice, and potential benefits do not reach the patient. ${ }^{24}$ Effective implementation strategies are necessary to ensure changes in practice to close the gap between research and practice. ${ }^{25}$ Again, much work is to be done. For instance, systematic reviews of implementation studies indicate at the moment variable effectiveness within the same implementation of interventions. These variations might be attributable to the effects of context and content; that is, implementation strategies that work for secondary care might, for example, not be feasible in primary care. ${ }^{26}$ More research is essential to understand 
in greater detail which factors influence the effectiveness of implementation interventions (outcome) in primary care setting (structure) for different kinds of targeted behaviors (process).

\section{Context}

The fourth focus deals with the policy context. Here the focus is on efficiency (cost-utility). Health services research looks at the various organizational components of health care delivery and the way they are related to outcomes. Primary health care has the responsibility to maximize gains in population health from finite budgets. The increasing costs of health care make the economic approach to health increasingly relevant; that is, choices in health care are needed to maintain (or restore) accessibility and equity. The discipline of family medicine, involved in the first point of contact between the patient and the health care system, has an important role to play in this debate. Consequently, underpinning statements with valid interdisciplinary research, taking into account the patient's perspective, is of utmost importance. Special interest is also needed in the study of changing health care services organization in countries in transition, such as certain eastern European and third world countries, and in the establishment of family medicine in these countries.

\section{Education}

Finally, the fifth focus deals with research in education. Departments of family medicine have often taken the lead in undergraduate medical curriculum innovation and new approaches in continuous medical education. Research is needed to assess the impact of different educational strategies.

In Figure 2 we have tried to apply the framework to research questions in relation to type 2 diabetes mellitus.

\section{CONCLUSION}

The answer to the rather superfluous question, "Why research in family medicine?" is simple: to perform bet-

Figure 2. Application of the framework to research on type 2 diabetes mellitus.

\begin{tabular}{|c|c|c|c|c|c|}
\hline Foci & Structure & Process & Outcome & $\begin{array}{l}\text { Research } \\
\text { Focus }\end{array}$ & $\begin{array}{l}\text { Research } \\
\text { Strategy }\end{array}$ \\
\hline $\begin{array}{l}\text { Basic } \\
\text { knowledge }\end{array}$ & $\begin{array}{l}\text { What do patients } \\
\text { know about long- } \\
\text { term risks of type } 2 \\
\text { diabetes mellitus? }\end{array}$ & $\begin{array}{l}\text { How do family physicians } \\
\text { inform their patients } \\
\text { about the long-term } \\
\text { risks? }\end{array}$ & $\begin{array}{l}\text { With which instruments } \\
\text { can we measure } \\
\text { the effect of extra } \\
\text { information on the } \\
\text { patient's compliance } \\
\text { with therapy and } \\
\text { follow-up? }\end{array}$ & Concepts & $\begin{array}{l}\text { Exploratory } \\
\text { descriptive, both } \\
\text { quantitative and } \\
\text { qualitative }\end{array}$ \\
\hline $\begin{array}{l}\text { Problem-solving } \\
\text { approach }\end{array}$ & $\begin{array}{l}\text { Can looking at } \\
\text { an educational } \\
\text { videotape improve } \\
\text { this knowledge in } \\
\text { a small group of } \\
\text { voluntary patients? }\end{array}$ & $\begin{array}{l}\text { Will the development of } \\
\text { a practice guideline } \\
\text { with special attention } \\
\text { to informing patients } \\
\text { about their disease make } \\
\text { doctors (an experimental } \\
\text { group of volunteers) give } \\
\text { more information to } \\
\text { their patients? }\end{array}$ & $\begin{array}{l}\text { Are better informed } \\
\text { patients more } \\
\text { compliant (tested } \\
\text { in an experimental } \\
\text { group of volunteers)? }\end{array}$ & Efficacy & $\begin{array}{l}\text { Experimental- } \\
\text { controlled }\end{array}$ \\
\hline Implementation & $\begin{array}{l}\text { Will distributing these } \\
\text { videotapes to all } \\
\text { patients improve } \\
\text { their knowledge of } \\
\text { diabetes? }\end{array}$ & $\begin{array}{l}\text { Will the introduction of this } \\
\text { guideline on a large scale } \\
\text { (sent by mail to all family } \\
\text { physicians) improve } \\
\text { giving information to } \\
\text { diabetics in general? }\end{array}$ & $\begin{array}{l}\text { Does a general increase } \\
\text { in the patients' } \\
\text { knowledge about } \\
\text { their illness lead to } \\
\text { a general increase in } \\
\text { compliance? }\end{array}$ & Effectiveness & Experimental \\
\hline Policy & $\begin{array}{l}\text { What is the cost of } \\
\text { this intervention } \\
\text { in relation to the } \\
\text { benefits? }\end{array}$ & $\begin{array}{l}\text { What is the cost of } \\
\text { developing and } \\
\text { distributing this } \\
\text { guideline in relation } \\
\text { to the benefits? }\end{array}$ & $\begin{array}{l}\text { Is the cost to achieve } \\
\text { this increase in } \\
\text { compliance in } \\
\text { balance with the } \\
\text { possible benefits, and } \\
\text { does this contribute } \\
\text { to more equity? }\end{array}$ & Efficiency & Health economics \\
\hline Education & $\begin{array}{l}\text { What should be the } \\
\text { content of a course } \\
\text { on diabetes care that } \\
\text { is focused on the } \\
\text { context of socially } \\
\text { vulnerable groups? }\end{array}$ & $\begin{array}{l}\text { Is role-playing an effective } \\
\text { way to teach students to } \\
\text { give clear information to } \\
\text { diabetic patients on their } \\
\text { disease? }\end{array}$ & $\begin{array}{l}\text { Do students effectively } \\
\text { learn to evaluate the } \\
\text { patient's compliance } \\
\text { during their } \\
\text { internships? }\end{array}$ & $\begin{array}{l}\text { Education } \\
\text { (knowledge, } \\
\text { skills, } \\
\text { attitudes) }\end{array}$ & Variable \\
\hline
\end{tabular}


ter for our patients. Realization of this goal is, however, complex. To succeed, research must take into account many different dimensions and foci and bear in mind the specificities of general practice. In this article we describe a framework that can help to map and clarify the different research questions. The framework stresses the relevance of family medicine research.

Primary care research questions and answers should be relevant to daily practice and comprise all domains of general practice, so that eventually most of the interventions in practice will be underpinned with medical, contextual, and policy evidence, and improvement of the quality of care through research will be finally achieved.

To read or post commentaries in response to this article, see it online at http://www.annfammed.org/cgi/content/full/2/suppl_2/S17.

Key words: Family practice; research; quality assessment/health care; education

A version of this paper was presented at the Wonca Research Conference, Kingston, Ontario, Canada, March 8-11, 2003.

Acknowledgments: J. De Maeseneer and A. De Sutter equally contributed to this paper. J. De Maeseneer formulated the core ideas and was involved in the final editing. A. De Sutter elaborated the literature and contributed to the final editing.

\section{References}

1. Allen J, Gay, B., Crebolder H, Heyrman J, Švab I, Ram P. The European definition of general practice/family medicine. 2002. Available at: http://www.euract.org/pap041.html.

2. Green LA, Fryer GE Jr, Yawn BP, Lanier D, Dovey SM. The ecology of medical care revisited. N Engl J Med. 2001;344:2021-2025.

3. Sheikh A, Smeeth L, Ashcroft T. Randomised controlled trials in primary care: scope and applications. Brit J Gen Pract. 2002;52:746-751.

4. Kjaergard LL, Villumsen JG, Huud C. Reported methodological quality and discrepancies between large and small randomised trials in meta-analyses. Ann Intern Med. 2001;135:982-989.

5. Di Blasi Z, Harkness E, Ernst E, et al. Influence of context effects on health outcomes: a systematic review. Lancet. 2001;357:757-762.

6. Anonymous. Is primary-care research a lost cause [editorial]? Lancet. 2003;361:977
7. Beck U. Risk Society: Towards a New Modernity. London: Sage Publications; 1992.

8. Douglas JDM. Is primary care a lost cause [letter]? Lancet. 2003;361: 1474.

9. De Maeseneer J, van Driel M, Green L, van Weel C. The need for research in primary care. Lancet. 2003;362:1314-1319.

10. Morse JM, Field PA. Qualitative Research Methods for Health Professionals. Thousand Oaks, Calif: Sage Publications; 1995.

11. De Maeseneer J, Derese A. Community oriented primary care. Eur J Gen Pract. 1998;4:49-50.

12. Rhyne R, ed. COPC: Health Care for the 21st Century. Washington, DC: American Public Health Association; 1998.

13. van Weel C. Biomedical science matters for people - so its impact should be better assessed. Lancet. 2002;360:1034-1035.

14. Donabedian A. Evaluating the quality of medical care. Milbank Mem Fund Q. 1966;44(3 Suppl):166-206.

15. De Maeseneer J. De zorg voor de kwaliteit en de kwaliteit van de zorg [The care for quality and the quality of care]. Huisarts Wet. 1993;36:437-439

16. van Weel C. Examination of context of medicine. Lancet. 2001;357: 733.

17. Deveugele M, Derese A, van den Brink A, Bensing J, De Maeseneer J. Consultation length in general practice : cross sectional study in six European countries. BMJ. 2002;325:472-477.

18. De Sutter Al, De Meyere MJ, De Maeseneer JM, Peersman WP. Antibiotic prescribing in acute infections of the nose and sinuses: a matter of personal habit? Fam Pract. 2001;18:209-213.

19. Mold J, Blake G, Becker L. Goal-oriented medical care. Fam Med. 1991;23:46-51.

20. Mold J, Green L. Primary care research: revisiting its definition and rationale. J Fam Pract. 2000;49:206-208.

21. van Weel C. General practice: a suitable place for clinical research. Eur J Gen Pract. 1995;1:6-7.

22. White KL. Fundamental research at primary care level. Lancet. 2000;355:1904-1906

23. Owen P. Clinical practice and medical research: bridging the divide between the two cultures. Brit J Gen Pract. 1995;45:557-560.

24. Cranney M, Warren E, Barton S, Gardner K and Walley T. Why do GPs not implement evidence-based guidelines? A descriptive study. Fam Pract. 2001;18:359-363.

25. Bero LA, Grilli R, Grimshaw JM, Harvey E, Oxman A, Thomson M Closing the gap between research and practice: an overview of systematic reviews of interventions to promote the implementation of research findings. BMJ. 1998;317:465-468.

26. Foy $R$, Eccles $R$, Grimshaw J. Why does primary care need more implementation research? Fam Pract. 2001;18:353-355. 